\title{
PENGEMBANGAN ALAT PRAKTIKUM PELAYANGAN BUNYI DAN EFEK DOPPLER BERBASIS MODUL MIKROFON KONDENSER DAN MIKROKONTROLER
}

\author{
Fathul Arifin $^{\text {a) }}$, Widyaningrum Indrasari ${ }^{\text {b) }}$, Cecep E Rustana ${ }^{\text {c) }}$ \\ Prodi Pendidikan Fisika Fakultas Matematika dan Ilmu Pengetahuan Alam, Universitas Negeri Jakarta Jalan \\ Rawamangun Muka No.1 Rawamangun, Jakarta Timur 13220 \\ Email: ${ }^{a)}$ fathul.nfr@gmail.com, ${ }^{\text {b) }}$ widyafisikaunj@gmail.com, ${ }^{\text {c) ce.rustana@yahoo.com }}$
}

\begin{abstract}
Abstrak
Gelombang bunyi merupakan salah satu materi sulit pada UN SMA. Terbukti dari turunnya persentase daya serap siswa dalam kurun waktu empat tahun terakhir, dengan rata-rata penurunan sebesar $15.3 \%$. Salah satu penyebabnya adalah media pembelajaran yang berkaitan dengan materi pelayang bunyi dan efek doppler masih sangat minim. Hasil dari analisis kebutuhan menunjukkan bahwa proses pembelajaran fisika di sekolah 39\% didominasi oleh pemberian tugas dan latihan soal. Namun, hanya 9\% saja pembelajaran fisika di sekolah dilakukan dengan kegiatan praktikum. Kegiatan praktikum pada materi pelayangan bunyi dan efek doppler yang dilakukan guru di sekolah kebanyakan masih menggunakan alat seadanya, dan hasil yang didapat merupakan data secara kualitatif. Sehingga pada penelitian ini dikembangkan alat praktikum pelayangan bunyi dan efek doppler dengan menggunakan mikrokontroler Arduino uno sebagai sistem kontrol, modul mikrofon kondenser sebagai penangkap sumber frekuensi, dan motor dc sebagai penggerak sumber frekuensi. Dari hasil pengujian, alat praktikum pelayangan bunyi dan efek doppler ini dapat bekerja dengan baik.
\end{abstract}

Kata-kata kunci: pelayangan bunyi, efek doppler, mikrofon condenser, motor dc.

\begin{abstract}
Sound waves is one of the difficult material on senior high school national examination. As evidenced by the decline in the percentage of absorption of students in the past four years, with an average decline of $15.3 \%$. One of the causes is learning media related to material beats and doppler effects are still very minimal. The results of the needs analysis show that the learning process of physics in schools is $39 \%$ dominated by assignments and exercises. However, only $9 \%$ of physics learning in schools is done by practical activities. Practical activities on material beats and doppler effects conducted by teachers in most schools still using a simple tools, and the results obtained are qualitative data. This research aims to develop practicum tool on material beats and doppler effects by using microcontroler Arduino uno as a system control, microphone condenser module as frequency source catcher, and motor dc as a frequency source driver. From the result of the test, the practicum tool of beats and doppler effects can work well.
\end{abstract}

Keywords: beats, doppler effect, microphone condenser, motor dc. 


\section{PENDAHULUAN}

Gelombang bunyi merupakan materi yang sulit dipahami oleh siswa. Berdasarkan hasil rekapan Ujian Nasional mata pelajaran Fisika tahun pelajaran 2017/2018, materi gelombang bunyi memiliki persentase daya serap paling rendah dibandingkan dengan materi lain yang diujikan. Selain itu tren nilai pada materi uji gelombang bunyi dalam empat tahun terakhir di Ujian Nasional selalu mengalami penurunan, dengan rata-rata penurunan per tahun sebesar $15.3 \%$ [1]. Penurunan nilai pada materi gelombang bunyi didasari oleh beberapa faktor yang teramati melalui pengambilan data melalui analisis kebutuhan, diantaranya 39\% kegiatan pembelajaran fisika di sekolah didominasi oleh pemberian tugas dan latihan soal, sementara hanya $9 \%$ saja yang melakukan pembelajaran dengan praktikum.

Laboratorium Fisika di sekolah biasanya melakukan praktikum dengan peralatan yang sederhana, sehingga belum dapat menunjukkan peristiwa pelayangan bunyi dan efek doppler secara konkret. Selama ini praktikum yang dilakukan oleh guru di sekolah hanya melakukan pengambilan data secara kualitatif dengan menggunakan alat kotak suara tabung resonansi. Sehingga tidak ada data yang dapat diolah untuk dianalisis. Oleh karena itu perlu dikembangkan alat praktikum pada materi pelayangan bunyi dan efek doppler yang dapat menampilkan data secara kuantitatif. Penelitian ini bertujuan untuk mengembangkan alat praktikum pelayangan bunyi dan efek doppler yang berbasis mikrokontroler yang dilengkapi modul mikrofon kondenser dan motor dc.

\section{METODOLOGI}

Metode penelitian yang digunakan adalah eksperimen dengan mengembangkan alat praktikum pelayangan bunyi dan efek doppler berdasarkan hasil pengukuran frekuensi yang berbasis mikrokontroler arduino uno sebagai sistem kontrol. Dalam pengembangan alat peraga ini, dilakukan studi komparasi dengan penelitian sebelumnya terkait alat peraga resonansi dan efek doppler [2] dan terkait konten materi [3-4]. Pada pengukuran frekuensi pelayangan bunyi digunakan modul mikrofon kondenser sebagai penangkap sumber frekuensi. Modul mikrofon kondenser lebih sensitif dan responsif terhadap bunyi dan sinyal yang dihasilkan lebih kuat dibandingkan dengan mikrofon jenis lain [5]. Untuk pengukuran frekuensi efek doppler pada sumber bunyi dimodifikasikan dengan kereta dinamika yang dilengkapi dengan motor dc. Motor dc merupakan perangkat elektromagnetis yang mengubah energi listrik menjadi energi mekanik.

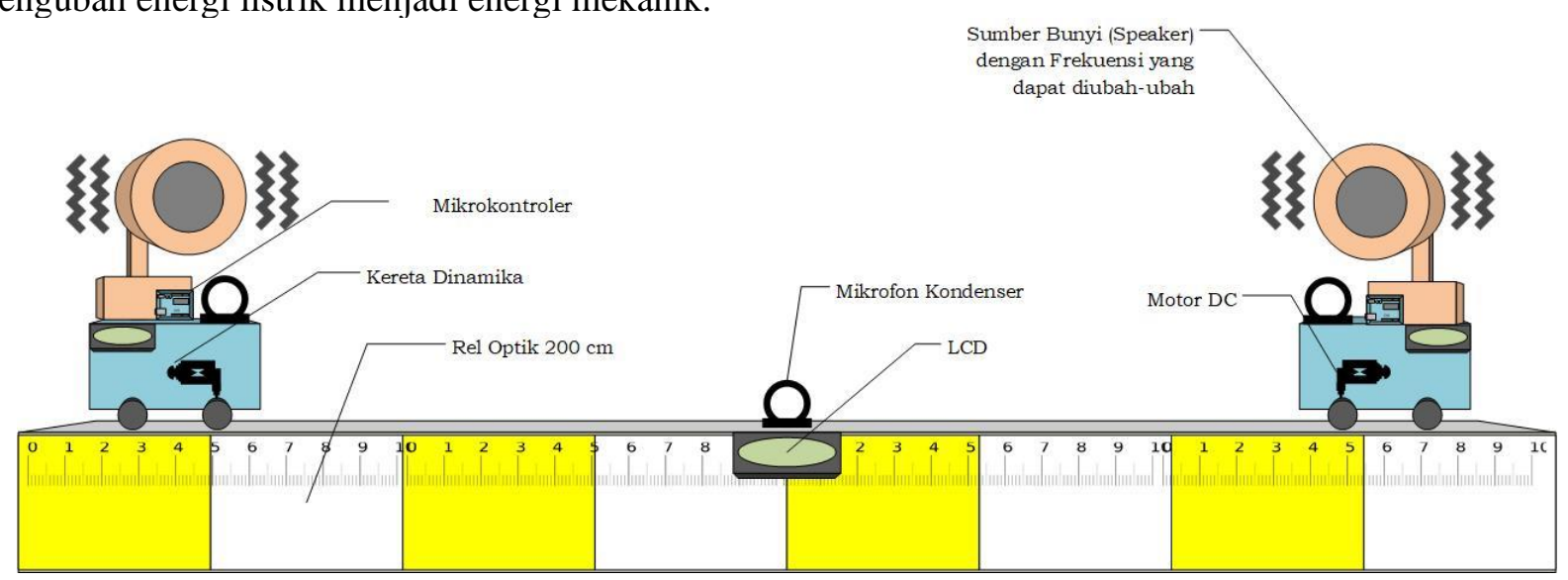

GAMBAR 1. Desain alat praktikum Pelayangan Bunyi dan Efek Doppler

Pada alat ini dua buah sumber frekuensi yang dikeluarkan melalui speaker. Sumber bunyi dengan frekuensi tertentu dibuat dengan mengggunakan aplikasi audacity dan kemudian di rekam dan disalurkan melalui speaker [6]. Untuk mengetahui frekuensi pelayangan dan jumlah pelayangan, frekuensi yang digunakan berselisih sangat tipis, agar gelombang yang teramati memiliki periode 
yang cukup besar untuk memudahkan dalam pengambilan data. Sumber bunyi yang sudah dimodifikasi bergerak dalam sebuah rel sepanjang $100-200 \mathrm{~cm}$, yang mengilustrasikan sumber bergerak mejauhi atau mendekati pengamat. Sumber dan pengamat dipasangkan display untuk mengetahui seberapa besar perubahan frekuensi yang terukur pada percobaan efek doppler, sedangkan untuk mengetahui frekuensi pelayangan bunyi dihitung secara manual, dan kemudian jumlah pelayangan dalam waktu tertentu diamati melalui tools serial plotter. Nilai pelayangan bunyi dapat dihitung dengan menggunakan persamaan berikut.

$$
f_{p}=n_{p}=\left|f_{1}-f_{2}\right|
$$

dengan fp adalah frekuensi pelayangan, np adalah jumlah pelayangan selama satu detik, f1 dan f2 adalah frekuensi sumber bunyi.

Sensor yang digunakan pada saat kalibrasai sebanyak tiga buah sensor suara. Sensor-sensor tersebut nantinya diletakan sesuai dengan gambar desain alat yang sudah terintegrasi dengan mikokontroler. Besar kesalahan relatif sensor dihitung dengan menggunakan persamaan berikut.

$$
\operatorname{Error}(\%)=\frac{|N s-N r|}{N r} \times 100 \%
$$

dengan Ns adalah nilai yang terbaca pada sensor yang digunakan, dan $\mathrm{Nr}$ adalah nilai sebenarnya yang telah diuji menggunakan alat laboratorium.

\section{HASIL DAN PEMBAHASAN}

\section{a. Sensor Suara}

Pada karakterisasi sensor suara dilakukan dengan membandingan nilai frekuensi yang dihasilkan dari aplikasi audacity, dan mencatat waktu yang dibutuhkan sensor dalam menangkap frekuensi pada tools serial plotter di aplikasi arduino IDE. Hasil pengukuran dirangkum pada TABEL 1. Kesalahan relatif pengukuran dapat dihitung dengan menggunakan persamaan (1).

\begin{tabular}{|c|c|c|c|c|c|c|}
\hline $\begin{array}{c}\text { Nilai } \\
\text { Frekuens } \\
\text { i }(\mathbf{H z})\end{array}$ & $\begin{array}{c}\text { Sensor } \\
1 \\
(\mathbf{H z})\end{array}$ & $\begin{array}{c}\text { Sensor } 2 \\
(\mathrm{~Hz})\end{array}$ & $\begin{array}{c}\text { Sensor } \\
\mathbf{3} \\
(\mathbf{H z})\end{array}$ & $\begin{array}{c}\text { Kesalaha } \\
\text { n Relatif } \\
1(\%)\end{array}$ & $\begin{array}{c}\text { Kesalaha } \\
\text { n Relatif } \\
\mathbf{2} \\
(\%)\end{array}$ & $\begin{array}{c}\text { Kesalaha } \\
\text { n Relatif } \\
\mathbf{3}(\%)\end{array}$ \\
\hline 50 & 47.62 & 47.08 & 48.54 & 4.76 & 5.84 & 2.92 \\
\hline 100 & 97.09 & 98.57 & 102.04 & 2.91 & 1.44 & 2.04 \\
\hline 150 & 153.06 & 148.35 & 145.63 & 2.04 & 1.10 & 2.91 \\
\hline 200 & 219.78 & 206.93 & 196.08 & 9.89 & 3.47 & 1.96 \\
\hline 250 & 235.85 & 237.12 & 240.38 & 5.66 & 5.15 & 3.85 \\
\hline 300 & 337.08 & 317.64 & 300.2 & 12.36 & 5.88 & 0.07 \\
\hline 350 & 372.08 & 351.71 & 333.33 & 6.31 & 0.49 & 4.76 \\
\hline 400 & 412.37 & 409.27 & 408.16 & 3.09 & 2.32 & 2.04 \\
\hline 450 & 478.72 & 458.95 & 441.18 & 6.38 & 1.99 & 1.96 \\
\hline 500 & 520.37 & 525.37 & 531.91 & 4.17 & 5.07 & 6.38 \\
\hline
\end{tabular}

TABEL 1. Data nilai frekuensi yang diterima sensor suara 


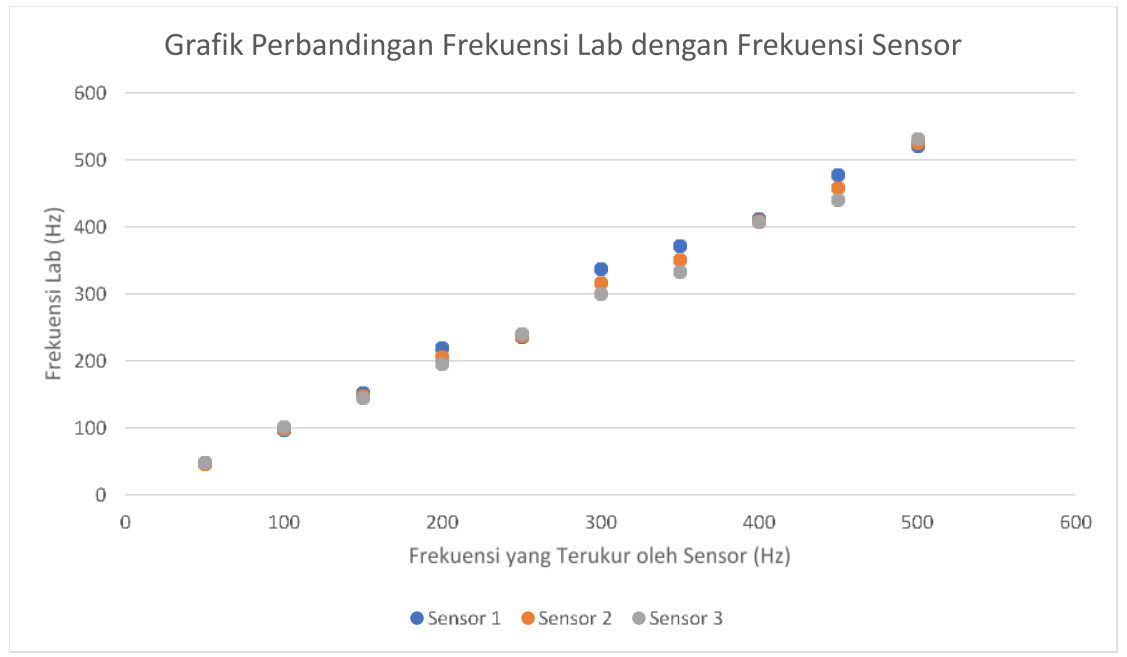

GAMBAR 2. Grafik hubungan nilai frekuensi lab dengan frekuensi sensor

\section{b. Pelayangan Bunyi}

Percobaan pelayangan bunyi dilakukan dengan sumber suara dengan frekuensi pertama sebesar $340.5 \mathrm{~Hz}$ dan frekuensi kedua sebesar $340.9 \mathrm{~Hz}$, dan amplitudo yang digunakan sebesar 0.4 $\mathrm{m}$. Kedua sumber frekuensi dengan amplitudo yang sama di mix dengan menggunakan aplikasi audacity, diperdengarkan melalui speaker selama $10 \mathrm{~s}$, sumber suara ditangkap sensor suara. Berikut ini adalah gambar yang ditampilkan pada tools serial plotter.

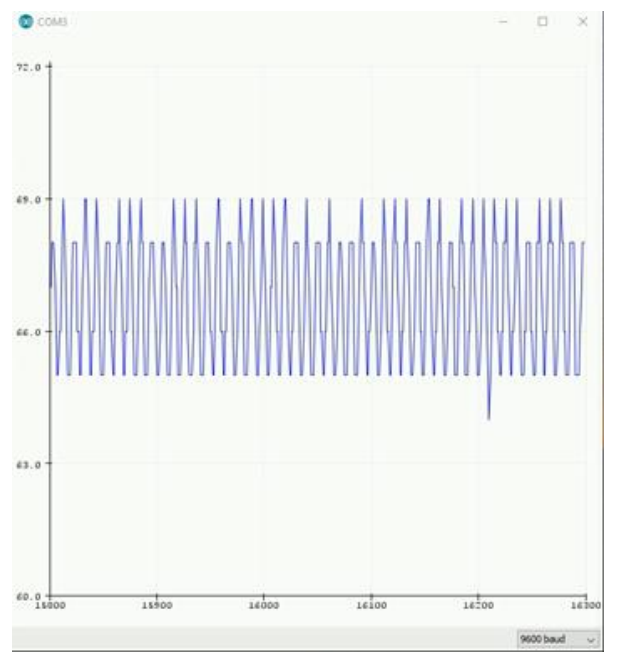

(a)

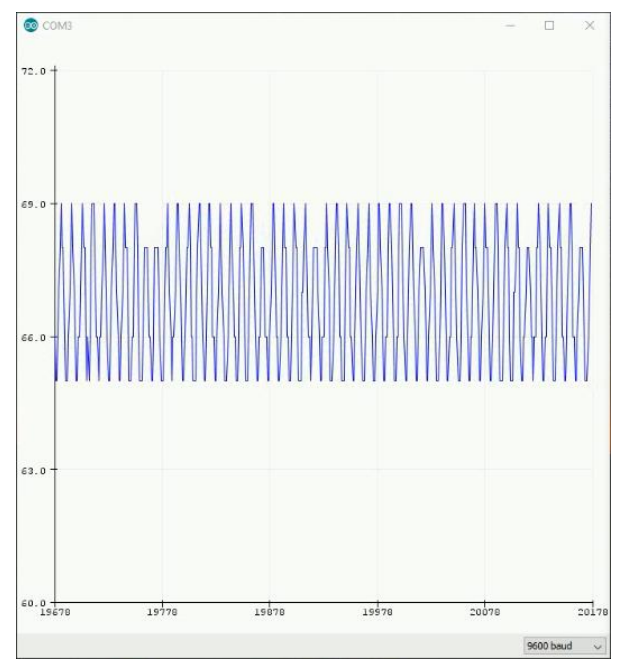

(b) 


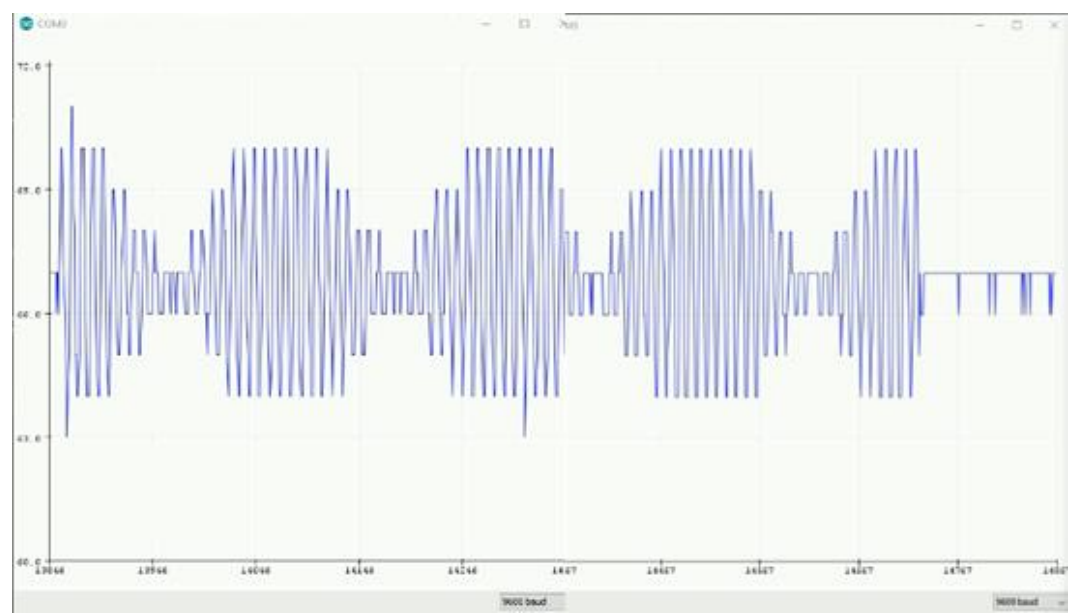

(c)

GAMBAR 3. (a) Frekuensi $340.5 \mathrm{~Hz}$ yang ditampilkan pada tools serial plotter, (b) Frekuensi $340.9 \mathrm{~Hz}$ yang ditampilkan pada tools serial plotter dan (c) Gabungan dari kedua frekuensi

Berdasarkan gambar diatas tampilan gelombang pada GAMBAR (c) menunjukkan peningkatan nilai amplitudo. Bentuk gelombang yang terlihat menjadi membesar dan mengecil disaat tertentu dan menghasilkan suara keras dan lemah. Hal ini diakibatkan karena kedua gelombang tidak dapat sefase pada setiap waktu, sehingga membentuk pola konstruktif dan destruktif.

Jumlah pelayangan dalam selang waktu $10 \mathrm{~s}$ juga dapat diamati dengan jelas. GAMBAR (c) menunjukkan ada 4 buah pelayangan bunyi yang terjadi selama $10 \mathrm{~s}$, atau 0.4 layangan setiap detiknya. Jumlah pelayangan dapat dihitung dengan menggunakan persamaan (1). Namun, tampilan tools serial plotter yang real time tidak bisa menampilkan secara penuh jika kedua buah sumber frekuensi dibunyikan selama $10 \mathrm{~s}$ yang menyebabkan tampilan gambar menjadi terpotong. Berikut ini adalah tabel beberapa percobaan pelayangan bunyi.

TABEL 2. Data nilai frekuensi pelayangan dan jumlah pelayangan

\begin{tabular}{cccc}
\hline $\begin{array}{c}\text { Frekuensi } \\
\mathbf{1}(\mathbf{H z})\end{array}$ & $\begin{array}{c}\text { Frekuensi } \\
\mathbf{2} \\
(\mathbf{H z})\end{array}$ & $\begin{array}{c}\text { Fpelayangan } \\
(\mathbf{H z})\end{array}$ & $\begin{array}{c}\text { Jumlah Pelayangan } \\
\text { dalam 10 s }\end{array}$ \\
\hline 340.2 & 340 & 0.2 & 2 pelayangan \\
340.9 & 340.5 & 0.4 & 4 pelayangan \\
340.8 & 340.2 & 0.6 & 6 pelayangan \\
340.8 & 340 & 0.8 & 8 pelayangan \\
341 & 340 & 1 & 10 pelayangan \\
\hline
\end{tabular}

Jumlah pelayangan selama $10 \mathrm{~s}$ diamati dari tools serial plotter pada aplikasi arduino IDE.

\section{c. Efek Doppler}

Percobaan efek doppler dilakukan dengan menggunakan dua buah frekuensi sumber yang masingmasing memiliki nilai $1135 \mathrm{~Hz}$ dan $1100 \mathrm{~Hz}$. Kecepatan kereta dinamika paling cepat sebesar 13.8 $\mathrm{cm} / \mathrm{s}$ dan kecepatan lambat sebesar $8.2 \mathrm{~cm} / \mathrm{s}$.

TABEL 3. Data hasil percobaan efek doppler 


\begin{tabular}{cccccc}
\hline $\begin{array}{c}\text { Frekuens } \\
\text { i Sumber } \\
(\mathbf{H z})\end{array}$ & $\begin{array}{c}\text { Kecepata } \\
\mathbf{n} \\
\begin{array}{c}\text { Sumber } \\
(\mathbf{m} / \mathbf{s})\end{array}\end{array}$ & $\begin{array}{c}\text { Kecepata } \\
\mathbf{n} \\
\text { Pengama } \\
\mathbf{t} \\
(\mathbf{m} / \mathbf{s})\end{array}$ & $\begin{array}{c}\text { Frekuensi } \\
\text { Pengamat } \\
(\mathbf{H z})\end{array}$ & $\begin{array}{c}\text { Frekuensi } \\
\text { Pengamat } \\
\text { Perhitungan } \\
(\mathbf{H z})\end{array}$ & $\begin{array}{c}\text { Kesalahan } \\
\text { Relatif }\end{array}$ \\
\hline 1135 & 0.082 & 0 & 1343.72 & 1135.27 & $18.36 \%$ \\
1100 & 0.138 & 0 & 1441.36 & 1100.45 & $30.98 \%$ \\
\hline
\end{tabular}

Berdasarkan tabel diatas terjadi kesalahan relatif yang cukup besar, dikarenakan beberapa faktor diantaranya frekuensi yang ditangkap tidak sesuai dengan frekuensi yang berasal dari sumber, kecepatan sumber terlalu pelan, rel yang ikut bergetar, dan suara motor dc yang bising, sehingga frekuensi yang terdengar tidak murni dari sumber.

\section{SIMPULAN}

Karakterisasi sensor yang telah dilakukan dengan menggunakan mikrokontroler arduino uno, maka dapat disimpulkan bahwa sensor suara dapat bekerja pada rentang frekuensi $50-500 \mathrm{~Hz}$. Sedangkan untuk kesalahan relatif maksimum sensor suara sebesar $12.36 \%$. Pada pengukuran pelayangan bunyi dapat dilakukan dengan melakukan pengamatan melalui tools serial plotter, dan mampu membaca jumlah pelayangan sampai dengan 10 pelayangan dalam waktu $10 \mathrm{~s}$. Sedangkan pada percobaan efek doppler masih perlu dikembangkan dengan memperhatikan beberapa faktor, karena kesalahan relatif yang terukur masih terlalu besar.

\section{REFERENSI}

[1] "Laporan Hasil Ujian Nasional." Internet: puspendik.kemendikbud.go.id/hasil-un/ [Feb. 19. 2019]

[2] M. C. Haisy, I. M. Astra, and E. Handoko, "PENGEMBANGAN ALAT PERAGA RESONANSI DAN EFEK DOPPLER BERBASIS SOUNDCARD PC/LAPTOP UNTUK MENINGKATKAN MOTIVASI BELAJAR FISIKA SISWA SMA", PROSIDING SNF, vol. 4, pp. SNF2015-II, Oct. 2015.

[3] H. Kurniawati, D. Desnita, and S. Siswoyo, "Pengembangan Media Pembelajaran Berbasis 3D PageFlip Fisika untuk Materi Getaran dan Gelombang Bunyi”, jpppf, vol. 2, no. 1, pp. 97 102, Jun. 2016.

[4] S. R. Hidayat, "Pengembangan Instrumen Tes Keterampilan Pemecahan Masalah pada Materi Getaran, Gelombang, dan Bunyi”, jpppf, vol. 3, no. 2, pp. 157 -166, Dec. 2017.

[5] Jamaluddin. dkk. "Perancangan dan Implementasi Sound Level Meter (SLM) dalam Skala Laboratorium sebagai Alat Ukur Intensitas Bunyi." Jurnal Pendidikan Fisika dan Aplikasinya (JPFA). vol. 4. No. 1. pp. 42-46. 2014

[6] I. A. Dwi Astuti. "Pengembangan Alat Eksperimen Cepat Rambat Bunyi dalam Medium Udara dengan Menggunakan Metode Time of Flight (TOF) dan Berbantuan Software Audacity" Unnes Physics Education Journal, vol. 5, pp. 18-24, Okt. 2016 